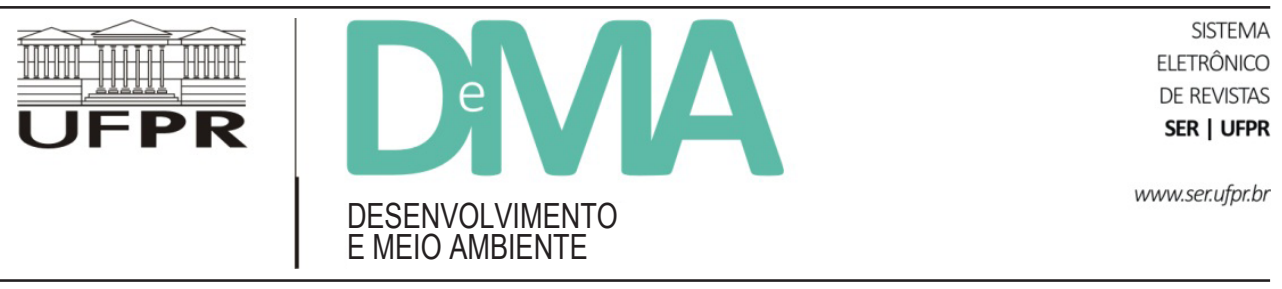

\title{
Fontes renováveis de energia elétrica e qualidade de vida em comunidades na Ilha do Marajó, Pará
}

\section{Renewable Electric Energy Sources and Quality of Life in Communities in the Marajó Island, Pará State}

\author{
Fabricio Quadros BORGES ${ }^{1 *}$, Nayara Carmona BARAÚNA¹, Jonathas Ribeiro CHOTOE ${ }^{1}$ \\ ${ }^{1}$ Universidade da Amazônia (UNAMA), Belém, PA, Brasil. \\ *E-mail de contato: doctorborges@bol.com.br
}

Artigo recebido em 17 de fevereiro de 2014, versão final aceita em 26 de março de 2015.

RESUMO: O objetivo deste estudo é analisar a qualidade de vida de comunidades da Ilha do Marajó, no Estado do Pará, a partir da implantação de fontes renováveis de geração de eletricidade. Diante da demanda de uso sustentável de fontes de geração de eletricidade e da necessidade de inserção socioeconômica de populações com acesso restrito a este insumo, esta investigação questionou até que ponto a implantação de projetos a partir de fontes renováveis de geração de eletricidade na Ilha do Marajó, especialmente de biomassa, solar e eólica, contribuíram para o padrão de vida das comunidades locais. A metodologia baseou-se em uma pesquisa de campo que utilizou entrevistas abertas junto a membros de quatro comunidades que se utilizaram destas fontes alternativas, em um total de 397 entrevistados. O estudo constatou que as comunidades registraram alto grau de satisfação com as novas fontes de geração e perceberam melhorias na qualidade de vida por meio de ganhos relativos na obtenção de renda e de acesso a eletrodomésticos. Porém, o acesso à renda de maneira substancial e permanente ocorreu apenas em uma das comunidades pesquisadas.

Palavras-chave: geração de eletricidade; fontes renováveis; qualidade de vida.

ABSTRACT: The purpose of this study is to analyze the quality of life of communities in the Marajo Island, in the state of Pará, after the deployment of alternative sources of electricity generation. Given the need for a sustainable use of sources of energy and the need for the social and economic inclusion of local population with limited energy access, the purpose of this study is to understand to what extent the implementation of projects for the use of alternative energy sources in Marajo, especially biomass, solar and wind, has contributed to the life standard of local communities. The methodology was based on a field study that used open-ended interviews with members of four communities that used these alternative sources, corresponding to 397 respondents. The study found that communities reported high satisfaction with the new generation sources and noticed improvements in life quality through relative gains in income and access to household appliances. However, access to income only occurred substantially and permanently in one of the communities surveyed.

Keywords: electricity generation; renewable sources; quality of life. 


\section{Introdução}

A disponibilidade das fontes de energia elétrica tem sido objeto de ampla discussão por parte dos governos de vários países que enfrentam desafios permanentes na medida em que procuram identificar fontes de geração de eletricidade capazes de atender suas demandas de maneira sustentável. Nesta perspectiva apresentam-se as fontes renováveis de energia. As fontes de energia renovável são aquelas em que os recursos que são usados não se esgotam, ou seja, possuem capacidade de regeneração. Aí se situam as fontes solar e hídrica, entre outras. Todavia, muitos países são extremamente dependentes de uma ou algumas poucas fontes de energia e precisam encontrar alternativas para diversificar suas fontes. Assim, destaca-se outro conceito importante, o de fontes alternativas, que são aquelas que se apresentam como alternativa de substituição ao uso de fontes mais tradicionais de energia. Estas fontes alternativas de energia são renováveis e podem gerar pouca ou nenhuma poluição, como a biomassa, por exemplo.

A geração de energia elétrica no Brasil baseia-se notadamente na utilização da força da água por meio de usinas hidrelétricas. Este quadro pauta-se na abundância de recursos naturais a baixos custos em termos relativos, notadamente na região amazônica. Porém, como destacam Tolmasquim et al. (2007), a questão que se coloca para o futuro é se o país terá condições de manter esta vantagem comparativa e ainda garantir à população o amplo acesso a este insumo. A geração de eletricidade no país cresceu a uma taxa média anual de 5\% ao longo dos anos de 1990 e de 2000. Durante esse período, a fonte hídrica respondeu por mais de $80 \%$ do total da energia elétrica gerada no país. Não somente a hidroeletricidade domina a geração de energia elétrica no Brasil, mas também grandes usinas dominam o setor, na medida em que existem cerca de 450 usinas hidrelétricas em operação (MME, 2012).

No Estado do Pará, situado na região amazônica brasileira, detentor de grandes potencialidades naturais e de notado potencial exportador de eletricidade, os desafios não estão apenas associados à garantia da disponibilidade deste insumo. A redução das desigualdades e da pobreza, a universalização do acesso à energia elétrica e a minimização dos custos e dos danos ambientais oriundos do uso da fonte hídrica são desafios que se impõem diante da realidade paraense. O seu importante potencial hidroelétrico a partir de grandes projetos implica bruscos impactos no ciclo hidrológico e mudanças no meio ambiente de modo geral (Junk \& Mello, 1990).

Diante deste panorama, destaca-se que o Estado do Pará precisa estar preparado para desenvolver outras fontes de geração, complementares à hídrica, diante do enfrentamento da insegurança na oferta de eletricidade e do desafio da problemática ambiental. Os projetos de geração de fontes alternativas a partir da biomassa, do sol e dos ventos devem ser objeto de estudos na intenção de conhecer os limites e potencialidade destes sistemas de geração. Os projetos de implantação de novas fontes alternativas de geração de eletricidade possuem a possibilidade de promover emprego e renda, de maneira a elevar as possibilidades de acesso à informação e à melhoria das condições de vida.

Na Ilha do Marajó, no Estado do Pará, algumas comunidades fazem uso de eletricidade oriunda de projetos de geração baseados em fontes renováveis. Esta condição se dá em virtude de serem comunidades isoladas, isto é, não vinculadas às linhas de transmissão que trazem energia da hidrelétrica de Tucuruí. Neste estudo, foram verificados quatro projetos localizados nas comunidades de Santo Antônio, Caxiuanã e Ilha de Araras.

A observação das condições de vida destas comunidades, a partir da implantação destes projetos de geração, cria condições para o levantamento de subsídios importantes para a avaliação das possibilidades de expansão destas fontes.

Neste sentido, esta investigação questiona: até que ponto a implantação de fontes renováveis de geração de eletricidade na Ilha do Marajó contribuiu para a melhoria do padrão de vida das comunidades locais? O objetivo deste estudo é analisar a qualidade de vida em quatro comunidades da Ilha do Marajó, no Pará, a partir da implantação de projetos de geração de eletricidade nestas comunidades baseados nas fontes biomassa, solar e eólica. Parte-se da hipótese de que o setor elétrico paraense não pode prescindir da diversificação de suas fontes de geração de eletricidade na medida em que esta ação representa uma resposta estratégica aos novos padrões de competitividade e este estudo compreende uma oportunidade de avaliar o alcance socioeconômico destas fontes de geração por meio destes projetos de geração. 


\section{Qualidade de vida e as energias renováveis}

\subsection{Qualidade de vida}

A complexidade que cerca o conceito ideal do termo qualidade de vida parece ser um consenso entre os pesquisadores, isto é, a multiplicidade dos fatores que podem determinar a qualidade de vida de um indivíduo ou de uma população (Costa Jr. et al., 2013). O termo qualidade de vida, em geral, é associado a uma expressão de fatores, como: satisfação no trabalho, estado de saúde, longevidade, lazer, salário, relações familiares, disposição, prazer e até espiritualidade (Nahas, 2003),

A qualidade de vida envolve a capacidade de um indivíduo, inserido em uma determinada sociedade, em avaliar e sintetizar todos os elementos fundamentais para estabelecer o padrão de conforto e bem-estar ideal para determinado espaço de tempo (Costa Jr. et al., 2013). Qualidade de vida é uma percepção humana que se assemelha ao grau de satisfação encontrado na vida familiar, amorosa, social e ambiental e à estética existencial (Minayo, 1992; Buss, 2000).

A mensuração da qualidade de vida compreende grande desafio. De acordo com Rameix (1997), mesmo que seja ainda um instrumento recente e vindo de uma tradição estrangeira, anglo-saxônica, empirista e utilitarista, é um fato irreversível que a qualidade de vida irá, possivelmente, pertencer ao nosso universo, da mesma maneira que a ecografia. Na tentativa de sintetizar a complexidade da noção de qualidade de vida e de sua relatividade, o autor destaca as diferentes culturas e realidades sociais, assim como os diversos instrumentos que têm sido elaborados. De acordo com Minayo (2000):

Apesar das justas críticas que tem recebido, o IDH tem sido bastante utilizado, inclusive no Brasil, e inspirado outros, como o Índice de Condições de Vida (ICV). Desenvolvido pela Fundação João Pinheiro, em Belo Horizonte, para estudar a situação de municípios mineiros, foi logo depois adequado, em consórcio com o IPEA, o IBGE e o PNUD para a análise de todos os municípios brasileiros. Instrumento muito mais sofisticado do que o IDH, com a vantagem de poder ser aplicado para 7 microrrealidades, o ICV é um composto de 20 indicadores em cinco dimensões: 1) renda (familiar per capita, grau de desigualdade, percentagem de pessoas com renda insuficiente, insuficiência média de renda e grau de desigualdade na população de renda insuficiente); 2) educação (taxa de analfabetismo, número médio de anos de estudo, percentagem da população com menos de 4 anos de estudo, percentagem da população com menos de 8 anos de estudo e percentagem da população com mais de 11 anos de estudo); 3) infância (percentagem de crianças que trabalham, percentagem de crianças que não frequentam escola, defasagem escolar média e percentagem de crianças com mais de um ano de defasagem escolar); 4) habitação (percentagem da população em domicílios com densidade média acima de duas pessoas por dormitório, percentagem da população que vive em domicílios duráveis e percentagem da população que vive em domicílios com instalações adequadas de esgoto) e 5) longevidade (esperança de vida ao nascer e taxa de mortalidade infantil).

Nesta discussão, destaca-se a contribuição didática de Nahas (2003), quando afirma ser a qualidade de vida uma condição humana resultante de dois conjuntos de parâmetros, os socioambientais e os individuais, modificáveis ou não, e que caracterizam as condições em que vive o ser humano. Ainda segundo o autor, esses conjuntos de parâmetros englobam diversos fatores que interferem de maneira determinante na qualidade de vida de um indivíduo ou de uma população.

Observam-se na Tabela 1 os parâmetros socioambientais e individuais mencionados por Nahas (2003), assim como os principais fatores que compõem cada um destes parâmetros.

TABELA 1 - Parâmetros da qualidade de vida e principais fatores de composição.

\begin{tabular}{ll}
\hline \multicolumn{1}{c}{$\begin{array}{c}\text { Parâmetros } \\
\text { Socioambientais }\end{array}$} & Parâmetros Individuais \\
\hline - Moradia & • Hereditariedade \\
- Transporte e segurança & - Estilo de vida \\
- Assistência médica & - Hábitos alimentares \\
- Condição de trabalho & - Controle do Estresse \\
- Remuneração & - Atividade física habitual \\
- Educação & - Relacionamentos \\
- Opções de lazer. & • Comportamento \\
\hline
\end{tabular}

FONTE: Nahas (2003). 
O termo qualidade de vida é citado diretamente no Relatório de Brundtland, quando afirma que a qualidade de vida e o bem-estar da sociedade são focos principais de consequência da prática do desenvolvimento sustentável, na medida em que a tentativa de satisfazer as necessidades do presente sem comprometer a capacidade de as futuras gerações satisfazerem suas próprias necessidades ocasiona reflexos na qualidade de vida. A ideia de desenvolvimento sustentável está alicerçada no tripé econômico, social e ambiental. A energia elétrica, na condição de um dos vetores de um processo de desenvolvimento, compreende um universo que deve ser objeto de planejamento público desde a escolha de fontes de geração deste insumo. A eletricidade é o fator chave para a industrialização, a urbanização, o crescimento econômico e a melhoria da qualidade de vida em sociedade (Khare et al., 2013).

\subsection{Energias renováveis no Estado do Pará}

Nesta perspectiva, as fontes renováveis de geração de energia elétrica devem estar sempre alinhadas à ideia do desenvolvimento sustentável. Os impactos causados pelo uso de determinadas fontes de geração de energia ocasionam perdas sociais e ambientais que comprometem de maneira irreversível a qualidade de vida de muitas populações. O Relatório de Brundtland é quem define o desenvolvimento sustentável com mais detalhamento. De acordo com o documento, de 1987, o termo é um processo de mudança no qual a direção de investimentos, a orientação do desenvolvimento tecnológico e a mudança institucional estão em harmonia e elevam os potenciais correntes e futuro para reunir necessidades e aspirações humanas (WCED, 1991). O Relatório apresenta uma relevante definição de crescimento, bastante discutida na pauta política internacional no que se refere às questões pertinentes à distribuição global de uso de recursos e à qualidade ambiental (Bruyn \& Drunden, 1999). A seguir, desenvolve-se uma abordagem sobre as fontes de geração de eletricidade no Estado do Pará a partir da biomassa, do sol e dos ventos.

No Relatório Brundtland destaca-se que desenvolvimento sem melhoria da qualidade de vida das sociedades não pode ser considerado desenvolvimento.
Isso equivale a dizer que em uma sociedade sustentável o progresso deve ser apreendido pela qualidade de vida e não pelo puro consumo material (Cavalcanti, 1997). Neste sentido, o planejamento sustentável do uso de fontes de geração de eletricidade pode fomentar a ampliação da qualidade de vida de populações. O clima também é pauta de discussão relevante. De acordo com Gaetani et al. (2014), o nexo entre as energias renováveis e o clima tem sido frequentemente investigado na perspectiva do impacto no clima global decorrente de um aumento da penetração das fontes renováveis na matriz energética mundial e a redução associada nas emissões de dióxido de carbono.

O Estado do Pará possui um significativo potencial de biomassa a partir de lenha e resíduos. O Estado é o terceiro maior beneficiador de espécies florestais do Brasil, consequentemente gerando grande quantidade de resíduos, o que representa potencial significativo para utilização dessa biomassa para fins energéticos. A lenha, compreendida como um conjunto de troncos de árvores, pedaços e lascas de madeira e gravetos, tem se destacado nos anos de 2000 como uma importante fonte de energia primária no Pará. Em 2005, a lenha participou com 47,6\% da oferta interna bruta de energia primária (BEEPA, 2007), porém, este insumo possui utilização ainda incipiente na geração de eletricidade no Estado.

A biomassa é um tipo de matéria que alimenta usinas a vapor de geração elétrica a partir de um processo de queima de elementos acumulados em um determinado ecossistema. Dentre os materiais mais utilizados citam-se o bagaço de cana e os materiais lenhosos. A queima de biomassa ocasiona a liberação de dióxido de carbono na atmosfera, porém, este composto foi anteriormente absorvido pelas plantas que deram origem ao combustível, o que proporciona um balanço de emissões de $\mathrm{CO}_{2}$ nulo (Borges \& Zouain, 2010).

A maior parte do potencial de biomassa, a partir de material lenhoso, encontra-se nos municípios paraenses do Sistema Interligado Nacional, podendo ser aproveitada para autoprodução, sendo viável também em muitos casos o transporte de biomassa para municípios componentes do sistema isolado. Além da lenha, os resíduos florestais, que compreendem todo o material florestal orgânico que sobra após a retirada da lenha, e os resíduos das madeireiras também podem ser utilizados 
como energia primária, sobretudo os resíduos oriundos de serrarias. De acordo com Padilha et al. (2005), o Pará possui cerca de 4.000 serrarias registradas formalmente e parte dos resíduos destas serrarias não tem destino certo, sendo queimados a céu aberto ou jogados nos rios, ocasionando significativos danos ambientais.

Quanto aos custos de utilização da biomassa, Padilha et al. (2005) observam que, levando-se em consideração que as usinas a vapor detêm custos menores de operação, se comparadas às usinas a diesel, e devido à atratividade técnica e econômica, as usinas termoelétricas podem ser implantadas com sucesso no Pará. Muitas mesorregiões apresentam sustentabilidade para o fornecimento de biomassa. A mesorregião do Marajó foi aquela que apresentou melhor possibilidade de aproveitamento da biomassa dentro da própria área, pois necessitou de pouca biomassa proveniente de outra mesorregião, uma vez que possui um potencial de geração com biomassa energética em torno de 16 MW. É relevante ainda acrescentar que materiais como papéis já utilizados, embalagens de papelão, sobras das toras e árvores perdidas pela explotação vegetal, galhos oriundos de poda de árvores em áreas urbanas e o pó de serragem, bastante comum na indústria madeireira do Pará, também podem ser amplamente utilizados como alimentos para termelétricas. É relevante ainda mencionar que estes materiais devem estar nas proximidades de termelétricas ou em rotas estratégicas com facilidade de acesso. A biomassa compreende uma fonte de baixo custo e menos poluente, que pode representar uma alternativa bastante razoável se estabelecida em média escala no Estado do Pará.

A fonte solar compreende mais uma alternativa de geração de eletricidade no Pará. A utilização do sol na geração de energia elétrica pode ocorrer de duas maneiras: indiretamente, gerada pelo uso do calor que alimenta uma central termelétrica, e diretamente, gerada pela utilização de painéis fotovoltaicos. A geração fotovoltaica tem tido muito mais aplicação, sobretudo para a alimentação de pequenos sistemas isolados, de projetos-piloto e de eletrificação de equipamentos solitários (Reis et al., 2005). Este tipo de fonte energética é considerado limpo, renovável e inesgotável. As principais desvantagens da fonte solar são: o alto custo de implantação de placas fotovoltaicas, muito onerosas para viabilizar a produção de eletricidade em grande escala, e sua irregularidade na forma de distribuição uniforme, o que requer grandes áreas de coleta e sistemas de armazenamentos. Todavia, como destaca Bermann (2003), a conversão fotovoltaica surge como alternativa de suprimento, de modo a promover: a geração de empregos locais; a manutenção da receita da produção e da comercialização da energia na própria região; e um processo de desenvolvimento autossustentado. Destaca-se, porém, que a simples conversão fotovoltaica não permite o desenvolvimento de atividades produtivas. Faz-se necessária a aplicação de outros mecanismos estratégicos capazes de difundir um processo de desenvolvimento socioeconômico consistente de acordo com as demandas e características econômicas locais.

O potencial de geração de empregos a partir da energia solar pode ser demonstrado por meio da composição dos segmentos da cadeia produtiva, desde o beneficiamento do quartzo (mineral não metálico de onde se extrai o silício, insumo dos painéis fotovoltaicos) até a produção e distribuição da energia solar propriamente dita. No tocante ao beneficiamento do quartzo, destaca-se que, de acordo com o Departamento Nacional de Produção Mineral (DNPM, 2005), o Pará possui reservas de quartzo da ordem de 1.627.994 t, notadamente em Breu Branco e Marabá, municípios pertencentes à mesorregião Sudeste do Estado, o que equivale a 36,6\% das reservas nacionais deste mineral. No Estado paraense, a utilização da fonte solar é indicada graças a uma grande quantidade de radiação solar de que dispõe durante todo o ano. Conforme Marques Filho e Dallarosa (2000), a Amazônia recebe, em média, 400 calorias por centímetro quadrado diariamente, das quais cerca de 120 referem-se ao território paraense, quantidade que é muitas vezes maior que a demanda do Estado paraense.

No tocante ao potencial de geração de empregos é oportuno destacar ainda que a biomassa também reúne condições potenciais para geração destes empregos. A capacidade de empregos gerados direta e indiretamente por uma central média de geração de eletricidade a partir da biomassa é de 300 empregos (Borges \& Zouain, 2010).

A energia eólica compreende outra possibilidade de fonte alternativa de geração no Pará. É oriunda de uma tecnologia que utiliza a força dos ventos que, por sua vez, opera turbinas ligadas a redes de eletricidade. 
Este tipo de fonte de energia, por classificar-se como fonte renovável, tende a crescer notadamente em países desenvolvidos, na medida em que é de natureza renovável, possui baixo custo de externalidades, não queima combustíveis fósseis e não emite gases poluentes que ocasionam o efeito estufa. Dentre as desvantagens desta fonte destacam-se: a alteração da paisagem quando da implantação de sua infraestrutura, composta por hélices e torres, a emissão de ruídos de baixa frequência, a ameaça a rotas migratórias de pássaros em virtude da utilização de grandes hélices enfileiradas e a improdutividade desta fonte em algumas regiões pela inconstância de ventos, baixa intensidade destes e desperdício de energia na ocorrência de fortes chuvas.

No território paraense registram-se ventos com velocidade entre 3,5 e 4 metros por segundo, em uma altura de 50 metros. De acordo com Silva (2005), se uma turbina eólica de $300 \mathrm{KW}$, com diâmetro de rotor de 33,4 metros, fosse instalada a partir da mencionada velocidade, produziria uma potência máxima entre 8,9 e $15 \mathrm{KW}$. Para o autor, estas velocidades seriam suficientes para operar turbinas eólicas com velocidades a partir de $3 \mathrm{~m} / \mathrm{s}$. No entanto, a velocidade de ventos entre 3,5 e $4 \mathrm{~m} / \mathrm{s}$, dominante no território paraense, está dentre as suficientes para apenas operar as turbinas eólicas em condições mínimas e Silva (2005) admite que estas turbinas jamais alcançariam um desempenho ótimo, o que não justifica um amplo programa de implantação de turbinas no Estado. O Estado do Pará possui grande parte de seu território com baixa densidade de ventos, o que não torna recomendada a utilização deste tipo de energia em larga ou mesmo em média escala (Rendeiro, 2003). O Pará ainda apresenta uma desvantagem para a utilização da energia eólica: a improdutividade desta fonte em algumas microrregiões do Estado pela inconstância de ventos, baixa intensidade destes e desperdício de energia na ocorrência de fortes chuvas. Conforme o IBGE (2008), as chuvas são abundantes no Pará, com a precipitação anual variando de $1.500 \mathrm{~mm}$, no sul do Estado, a 3.500 $\mathrm{mm}-4.000 \mathrm{~mm}$, no estuário do rio Amazonas.

Diante deste contexto de abordagem, observa-se, conforme Gaetani et al. (2014), que os limites tecnológicos e econômicos para a alta penetração de energias renováveis no sistema de energia elétrica ainda existem, na maior parte, relativos ao armazenamento de flexibilidade de rede e energia necessária para incorporar a geração de eletricidade a partir de fontes intermitentes na rede de transporte. E as proporções continentais do Estado paraense contribuem ainda mais para este percalço.

\section{Estratégia metodológica}

Este estudo é classificado quanto aos fins e quanto aos meios conforme a taxionomia de Vergara (2009). Quanto aos fins, é exploratório e descritivo. É exploratório na medida em que envolve um levantamento de dados que estimula a compreensão da dinâmica da necessidade de uso de novas fontes de geração de eletricidade no Pará. E é descritivo no momento em que descreve aspectos pertinentes ao padrão de vida das comunidades pesquisadas a partir do uso destas fontes de geração. Quanto aos seus meios, é classificado como uma pesquisa de campo na medida em que se utilizou de entrevistas junto a indivíduos de comunidades da Ilha do Marajó na intenção de verificar suas condições de vida.

O local de estudo nesta investigação foi a Ilha do Marajó, pertencente ao Estado do Pará. Localizada na foz do rio Amazonas, a Ilha possui uma área de aproximadamente $40.100 \mathrm{~km}^{2}$ e registra as coordenadas geográficas 00'43'25" de latitude Sul e 48 $30^{\circ}$ '29" de longitude Oeste. É a maior Ilha costeira fluviomarítima do mundo e possui cerca de 250.000 habitantes (Infoescola, 2013). A capital do Estado do Pará, Belém, localiza-se a sudeste do canal que separa a Ilha do continente.

A pesquisa realizou-se em três etapas: coleta de dados, tratamento dos mesmos e análise de resultados. O processo de coleta de dados englobou o período entre março de 2011 e outubro de 2012 e se utilizou de entrevistas abertas junto a indivíduos de quatro comunidades pesquisadas, em um total de 397 entrevistados. As localidades são: Santo Antônio, localizada no município de Breves (Projeto Marajó), Ilha de Araras, situada no município de Curralinho (Projeto Araras I e Projeto Araras II) e Caxiuanã, localizada em Melgaço (Projeto Caxiuanã).

A seguir, na Tabela 2, observam-se as comunidades e os projetos de geração de energia elétrica a partir de fontes alternativas que foram observados nesta investigação. Os projetos são financiados pelo Programa de 
TABELA 2 - Dados sobre os projetos em operação de geração de eletricidade a partir de fontes alternativas na Ilha do Marajó, Pará.

\begin{tabular}{ccccccc}
\hline Local & Comunidade & Projeto & Fonte & $\begin{array}{c}\text { Capacidade } \\
\text { instalada de } \\
\text { geração (KW) }\end{array}$ & $\begin{array}{c}\text { Demanda } \\
\text { atendida } \\
\text { (n } \mathbf{n}^{\mathbf{0}} \text { residências) }\end{array}$ & $\begin{array}{c}\mathbf{N}^{\mathbf{0}} \text { de } \\
\text { entrevistas }\end{array}$ \\
\hline Breves & Santo Antônio & Marajó & Biomassa & 200 & 17 & 56 \\
Curralinho & Ilha de Araras & Araras I & Solar & 50 & 150 & 148 \\
Curralinho & Ilha de Araras & Araras II & Eólica & 25 & 80 & 161 \\
Melgaço & Caxiuanã & Caxiuanã & Solar & $*$ & 11 & 32 \\
\hline
\end{tabular}

FONTE: Elaborado pelos autores.

* Dados não divulgados pelo projeto.

Incentivo às Fontes Alternativas de Energia Elétrica do governo federal e operados pela Universidade Federal do Pará, Projeto GEDAE.

As comunidades recebem a eletricidade sem ônus durante todo o funcionamento do projeto, cerca de dois anos. Em seguida, abordam-se brevemente os objetivos e os custos de manutenção destes projetos.

O Projeto Marajó foi elaborado pelo Grupo de Energia Biomassa \& Meio Ambiente - EBMA. Sua estruturação e operação foram resultadas de uma análise realizada pelo professor por um período de aproximadamente um ano pelo arquipélago do Marajó, juntamente com uma equipe de pesquisadores da UFPA, com a finalidade de conhecer o potencial de biomassa que a região apresenta, resultando na implantação do Projeto Marajó na comunidade de Santo Antônio, ilha Siriri. Os custos gerados pelo funcionamento da usina são absorvidos pelos recursos captados com o comércio praticado na ilha, sendo eles o pagamento de mão de obra para a colocação dos resíduos dentro do forno gaseificador, frete da balsa que eventualmente complementa os resíduos de madeira (estes são doados por outras serrarias) e a compra de diesel para o aquecimento do sistema realizado pela CMSA. Contudo, em períodos de baixa no comércio de peixes e fechamento de serrarias por parte de fiscalizações ambientais, o sistema opera abaixo de sua capacidade ou não opera por falta de insumo vegetal.

O Projeto Araras I possui o objetivo de avaliar potencialidades a partir da energia solar na localidade. $\mathrm{O}$ sistema fotovoltaico utilizado na Ilha de Araras é bastante abrangente e atende em torno de 150 famílias, com uma população de aproximadamente 600 habitantes. O sistema fotovoltaico é exclusivamente fornecedor de energia para a comunidade, entretanto, possui grupo gerador diesel para possíveis emergências. Os custos gerados pela utilização do sistema são em torno de R $\$ 7.000$ a R \$ 10.000 o $\mathrm{KW} / \mathrm{h}$, valores considerados elevados mesmo analisando equipamentos de operação e custos para manutenção. $\mathrm{O}$ tempo estimado para implantação e utilização do sistema foi em torno de um ano e meio, porém, as pesquisas iniciais sobre a escolha da área e o potencial das ilhas ao entorno de Breves começaram em 2007.

O Projeto Araras II tem o propósito de avaliar as potencialidades eólicas na localidade. O sistema utilizado nas comunidades da Ilha das Araras II atende em torno de 80 famílias com pelo menos seis filhos, com cerca de 480 pessoas beneficiadas. A geração de energia dessas comunidades é exclusivamente fornecida pelo sistema eólico; em casos isolados, ocorreram breves interrupções ao longo do dia, provenientes da baixa carga das baterias. A manutenção do sistema é efetuada pela mesma empresa fornecedora das hélices e, apesar de o sistema eólico caracterizar-se na região como eficiente e promissor não é cobrada nenhuma taxa de utilização, fornecimento e manutenção do sistema. A verificação das cargas das baterias e seu eventual desligamento, em casos de necessidade, ocorrem a cargo de um morador local, que ajuda a coordenar o racionamento de energia para que seja utilizada em situações necessárias e nos horários relevantes do dia.

O Projeto Caxiuanã foi implantado pelo Grupo de Estudos e Desenvolvimento de Alternativas Energéticas - GEDAE/UFPA - com o propósito de minimizar os custos com combustível para geradores a óleo diesel e atender aos moradores localizados nos arredores da Estação. O sistema é composto por 104 módulos fotovoltaicos, 
com 60 baterias e uma capacidade instalada de 8,7 KW que atende parte da demanda da Estação Científica e 24 residências durante 24 horas. Foi um dos maiores sistemas fotovoltaicos já implantados na região em sua época. O projeto não necessita de operação, sendo totalmente autônomo, ficando a cargo da Estação apenas a limpeza do local e a proteção contra possíveis danos provocados nas placas ou baterias. $\mathrm{O}$ atendimento do sistema é de 24 horas dentro e fora da Estação, ocorrendo eventuais quedas de eletricidade ocasionadas por momentos de alta demanda, normalmente em períodos noturnos. Os aparelhos que demandam maior carga elétrica não são utilizados com energia do sistema, ficando esta reservada apenas para a operação de geladeiras, freezers, ventiladores e lâmpadas fluorescentes.

A seleção das comunidades para a pesquisa de campo se deu em função destas sediarem projetos de geração de eletricidade a partir de fontes alternativas baseadas na utilização de recursos naturais locais. $\mathrm{O}$ tratamento de dados realizou-se por meio da organização e da sistematização destes dados na intenção de possibilitar a identificação de possíveis melhorias no padrão de vida das comunidades pesquisadas a partir da implantação das fontes alternativas de geração de eletricidade. A investigação optou pela realização de um tratamento de dados que forneceu notadamente resultados percentuais na medida em que estes possibilitam uma percepção mais representativa e de fácil compreensão do panorama de inserção socioeconômica das comunidades a partir dos projetos de fontes de geração implantados. Por fim, desenvolveu-se a análise de resultados, que examinou variáveis indicativas de qualidade de vida nas comunidades pesquisadas. A análise utilizou alguns dos parâmetros socioambientais mencionados por Nahas
(2003), que foram selecionados. Estes parâmetros podem ser observados na Tabela 3.

A análise de dados optou pela escolha dos parâmetros socioambientais por possuírem maiores condições de representação global das condições de vida de uma comunidade e selecionou os fatores moradia, condição de trabalho, segurança e assistência médica como representantes destes parâmetros em virtude da disponibilidade de acesso para a obtenção de dados precisos.

\section{Resultados e discussão}

Esta seção foi elaborada de maneira a procurar possibilitar as diversas percepções necessárias ao leitor para uma avaliação mais abrangente e sistematizada. Neste sentido, esta discussão foi composta de seis partes. São elas:

(i) o envolvimento dos indivíduos com a instalação dos sistemas de geração de eletricidade;

(ii) a constância no fornecimento de energia elétrica;

(iii) o grau de satisfação destas famílias com a energia gerada a partir de fontes alternativas;

(iv) o número de eletrodomésticos por residência;

(v) as famílias com acesso a renda devido à implantação dos sistemas; e

(vi) a percepção do desenvolvimento socioeconômico nas comunidades envolvidas.

No que tange ao envolvimento das pessoas com o processo de instalação dos sistemas de geração (Figura 1), as comunidades de Santo Antônio (100\%) e de Araras II $(100 \%)$ foram as únicas que participaram ativamente do projeto em todas as fases.

TABELA 3 - Parâmetros socioambientais da qualidade de vida e sua descrição.

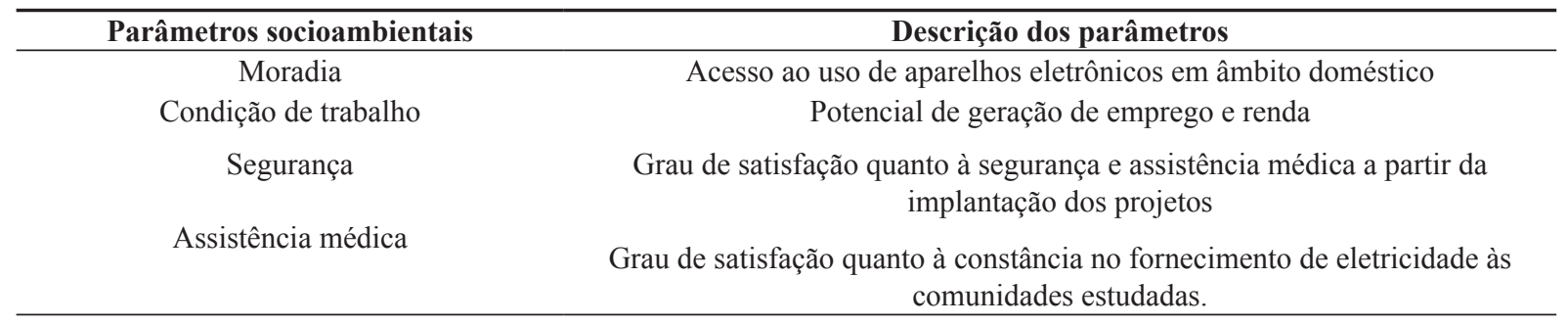

FONTE: Adaptado pelos autores a partir de Nahas (2003). 


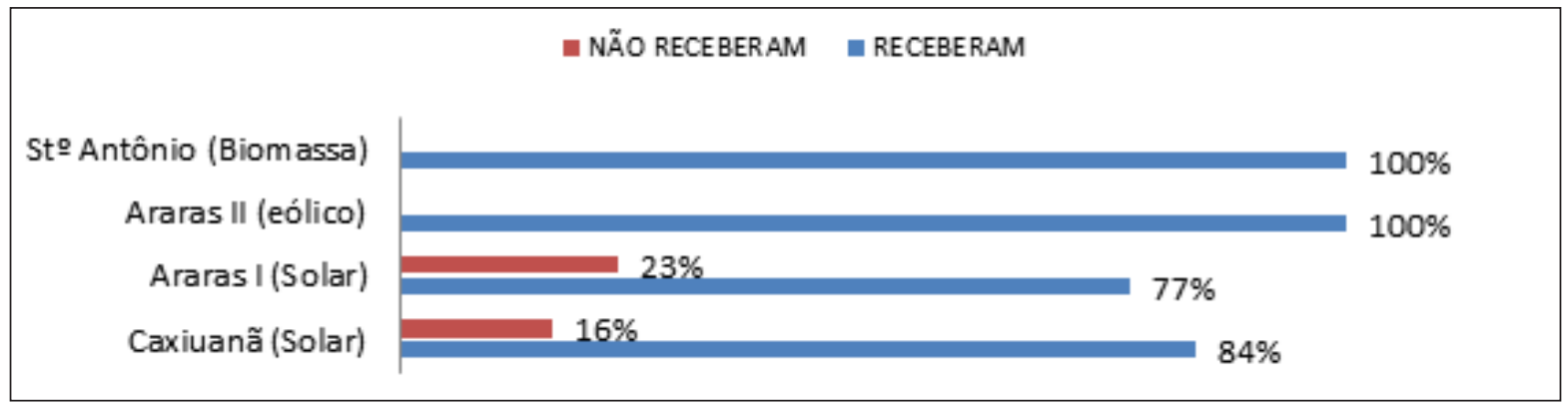

FIGURA 1 - Instruções à comunidade sobre o funcionamento do sistema de geração.

FONTE: Elaborado pelos autores.

Na comunidade de Santo Antônio foi implantado um sistema a vapor $200 \mathrm{~kW}$, que usa resíduos de serrarias próximas, projeto CENBIO/USP e UFPA. A administração é exercida pela associação dos moradores, que elege um membro da comunidade para cuidar e gerir os recursos utilizados e provenientes da atividade do sistema. Isso garante a sustentabilidade de operação e manutenção do sistema gerador.

Em Araras II utiliza-se um aerogerador que fornece energia para a comunidade. Nesse tipo de sistema gerador de eletricidade não há necessidade de interação constante com os beneficiados, ficando a cargo da comunidade apenas o cuidado com danos ocorridos por ação humana ou por falta de limpeza do terreno onde esta instalada a torre eólica. A participação dessa comunidade se deu por meio de auxílios com alimentação e hospedagem para os executores do projeto, tendo alguns incluídos na fase de instalação do mesmo em momentos de trabalho braçal ou similar.

Na comunidade de Araras I, que possui um sistema fotovoltaico, verificou-se que $23 \%$ dos entrevistados afirma não ter recebido instruções por parte dos executores do projeto. Muitos moradores alegaram que os técnicos apenas informavam onde iriam instalar, sem explicar maiores detalhes. Esse fato possui duas interpretações: a primeira é que esta parcela se caracteriza por pessoas que estiveram ausentes em certos momentos, durante o período de implantação, seja por motivo de trabalho ou desinteresse. A segunda consiste na necessidade de a mão de obra técnica empregada na execução ser especializada, dado o perfil técnico que o sistema exige, totalmente eletrônico e de autorregulação.
A comunidade de Caxiuanã, por sua vez, obteve instruções por meio dos técnicos da reserva e do GEDAE/UFPA, além de participar de reuniões onde a população assistia a palestras sobre as formas de utilizar a eletricidade de maneira econômica e os benefícios para o meio ambiente trazidos por ela. Quando comparadas as comunidades de Araras I e Caxiuanã, alimentadas pela mesma fonte de geração elétrica, verificaram-se duas realidades distintas. A primeira teve seu sistema implantado pela SS Solar, uma empresa privada que tinha somente o objetivo de fornecer um serviço ao governo, não tendo nenhum vínculo com a comunidade. Na segunda, a comunidade vive ao redor da Estação Ferreira Penna, mantendo uma relação harmoniosa com a mesma, onde há troca de experiências e conhecimento entre a população nativa e os pesquisadores, o que fez com que apenas $16 \%$ dos entrevistados afirmassem não ter recebido instruções sobre o funcionamento do sistema de geração.

Quanto à constância no fornecimento de energia elétrica (Figura 2) verificou-se, no geral, indicativos positivos na maior parte das comunidades. Esta contância no fornecimento de eletricidade revelou relação, por parte dos entrevistados, com a melhoria das condições de segurança e assistência médica, que compreendem fatores de composição dos parâmetros socioambientais de Nahas (2003).

Na comunidade de Santo Antônio, foi verificado que $63 \%$ das pessoas entrevistadas consideram não ocorrer momento de descontinuidade da energia eletrica ofertada. Os demais entrevistados mencionam interrupções oriundas basicamente da ausência de insumos para a 


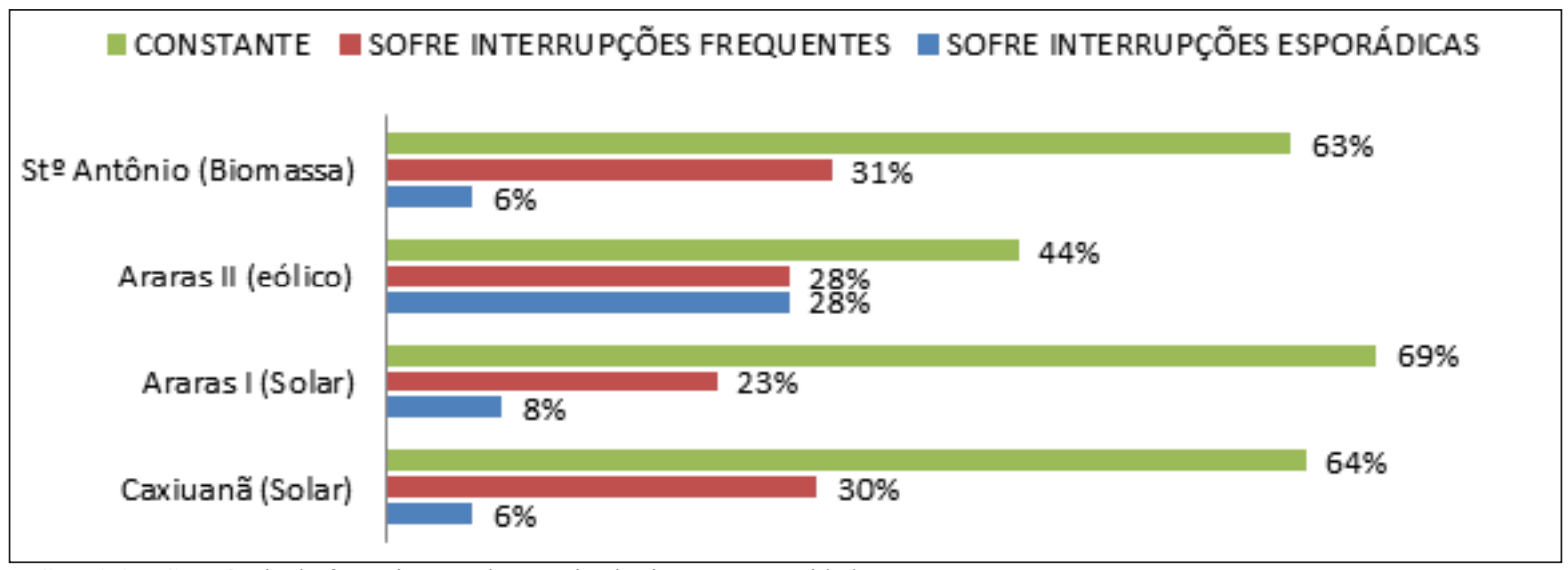

FIGURA 2 - Constância do fornecimento de energia elétrica nas comunidades.

FONTE: Elaborado pelos autores.

alimentação do sistema a vapor. Em algumas residências existem geradores a diesel utilizados em momentos de emergência, seja por problemas de insumos da usina ou por incapacidade momentânea do sistema, o que pode ter causado a falsa impressão de um fornecimento constante para a maioria dos entrevistados. $\mathrm{O}$ fornecimento foi classificado como constante para a maior parte dos entrevistados em Araras I (69\%) e Caxiuanã (64\%). O sistema é fotovoltaico e localiza-se próximo às residências.

$\mathrm{Na}$ comunidade de Araras II, onde se verificou o mais baixo registro de constância no fornecimento (44\%), observou-se a existência de um número muito grande de residências que sobrecarregam a oferta de eletricidade gerada, pois a comunidade expandiu-se e, junto com isso, o seu poder de adquirir bens eletrônicos, ocasionando quedas no fornecimento de energia. Entretanto, ocorre de forma homogênea em toda a comunidade devido ao fato de nem todas as famílias possuírem equipamentos eletrônicos. De maneira mais discreta, esta expansão e o aumento na aquisição de equipamentos elétricos de uso doméstico é uma característica que vem aumentando nas comunidades pesquisadas, levando-as a uma incompatibilidade entre a oferta de energia e a demanda apresentada.

Na pesquisa sobre a satisfação dessas pessoas com o fornecimento de eletricidade para cada comunidade, percebe-se, conforme a Figura 3, que a comunidade de Araras II foi a que demonstrou o maior grau de satisfação com a energia fornecida (72\%). Este fato se atribui, em grande parte, à localização desta comunidade em área antes não atendida pela eletricidade e pela possibilidade de melhoria das condições de segurança e assistência médica, que compreendem mais dois fatores de composição dos parâmetros socioambientais de Nahas (2003).

As comunidades de Araras I (46\%) e Caxiuanã (48\%) apresentaram uma margem significativa de satisfação, embora tenham demonstrado alguns pontos de descontentamentos com o fato de a eletricidade não ser fornecida de maneira constante. Em Santo Antônio é notável, dentre as demais, um grau de aceitação pela energia fornecida, porém, com uma frustação, por parte de alguns moradores, pelo fato de que seu fluxo ocorre em períodos fixos e possui limitações quanto ao nível de tensão oferecido, especialmente quanto à intensidade de corrente.

Por meio das entrevistas nas comunidades, quando da verificação do grau de satisfação dos moradores com a eletricidade fornecida pelo sistema de geração implantado, observou-se que a sensação de qualidade de vida é uma percepção que é semelhante ao nível de satisfação verificado na vida em família e em âmbito social, que compreende dois dos fatores mencionados por Minayo (1992) e Buss (2000) quando os autores procuram estabelecer uma definição para qualidade de vida.

De acordo com as entrevistas realizadas junto aos moradores locais, o acesso ao fornecimento de eletrici- 


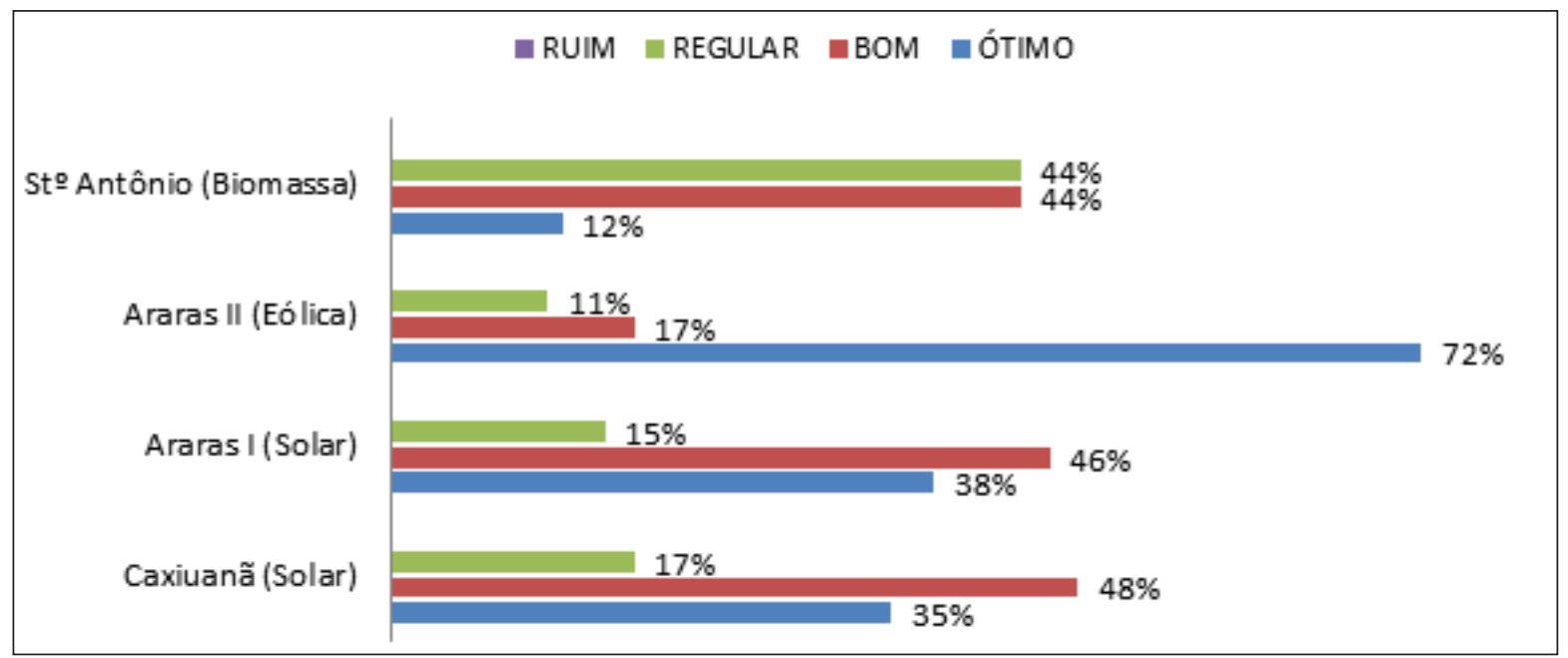

FIGURA 3 - Grau de satisfação dos moradores com a eletricidade fornecida pelo sistema. FONTE: Elaborado pelos autores.

dade e a diminuição de custos com óleo diesel fizeram com que as populações obtivessem um excedente de renda que foi destinado para a compra de equipamentos eletrônicos ou máquinas que dependem de energia elétrica para operarem. A comunidade de Araras II é a que possui o maior número de aparelhos elétricos (Figura 4), onde $78 \%$ dos entrevistados possuem mais de 3 eletrodomésticos. O número de aparelhos elétricos compreende um relevante elemento contribuinte ao fator moradia, que compõe os parâmetros socioambientais de Nahas (2003). A estrututura de acesso por meio de atividades econômicas diversificadas e sua organização comunitária, que envolve igreja, escolas e centro de eventos, favorecem a disseminação de acesso a estes aparelhos domésticos, que são adquiridos a partir da renda gerada.

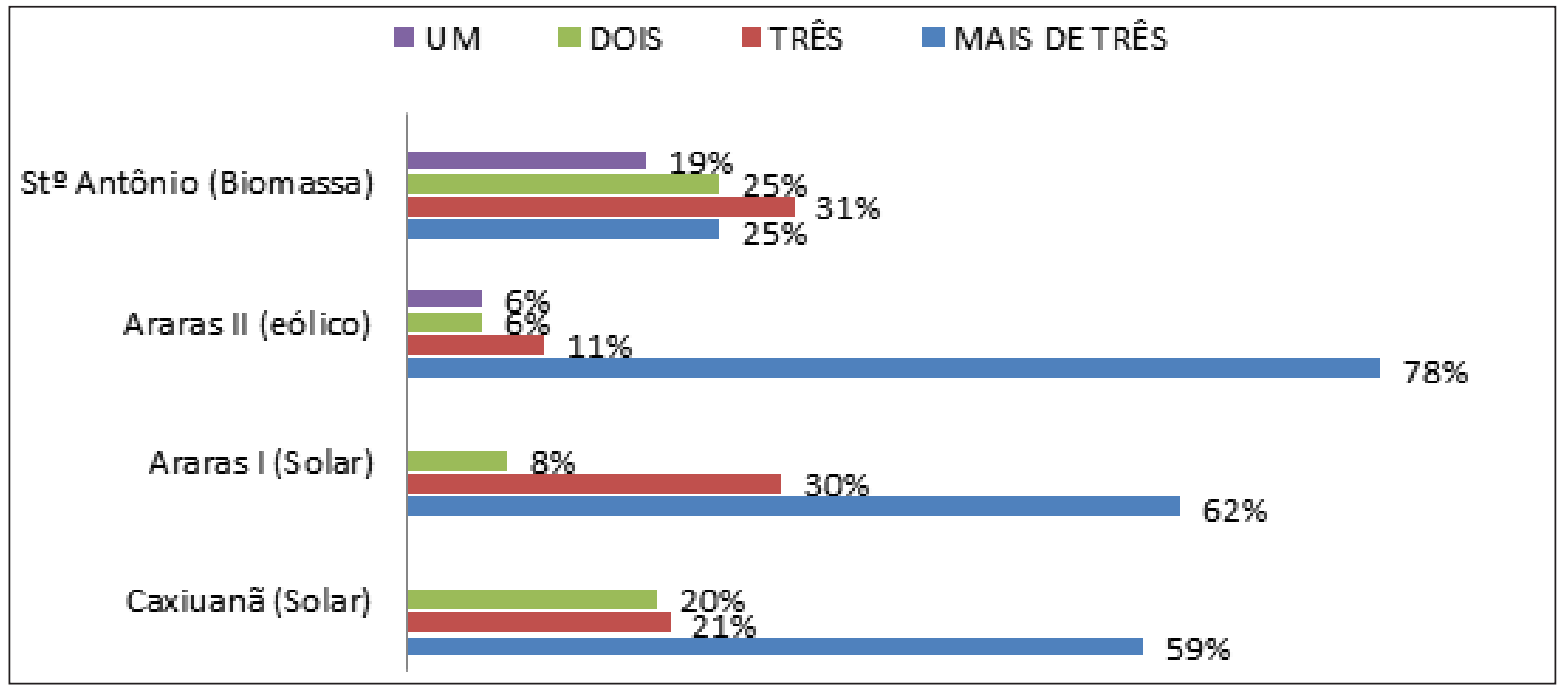

FIGURA 4 - Número de aparelhos elétricos por residência.

FONTE: Elaborado pelos autores. 
Na comunidade de Santo Antônio observou-se o menor número de aparelhos por residência, onde apenas $25 \%$ dos entrevistados possuem mais de três eletrodomésticos. Isso pode ser ocasionado pelo afastamento que a comunidade possui em relação às demais regiões pesquisadas e na maioria delas uma família mantém laços familiares com a outra, havendo um compartilhamento de aparelhos que acabam atendendo mais de uma família.

Quanto ao acesso a renda por parte das famílias (Figura 5), verificou-se que a maioria dos entrevistados afirmou que o sistema implantado em suas respectivas comunidades beneficiou-os de modo direto ou indiretamente com relação ao acesso a alguma forma de renda, seja por produção de alimentos que necessitam de refrigeração ou com a conservação de pescados para posterior comercialização. Todo este contexto caracteriza uma melhoria nas condições de trabalho proporcionada pela implantação dos sistemas de geração de energia elétrica a partir de fontes alternativas. Destaca-se que estas condições de trabalho compreendem outro fator de composição dos parâmetros socioambientais de Nahas (2003).

Na comunidade de Santo Antônio, todos afirmaram ter tido maior acesso a renda após a implantação do sistema, fato relacionado com as finalidades que o mesmo tem na Ilha, ou seja, o sistema gera energia que é empregada no consumo das famílias e simultaneamente no funcionamento de uma fábrica de gelo que pertence à cooperativa da comunidade. O lucro resultante é convertido para a manutenção do projeto e para a própria comunidade. Aliada a isso se tem a localização da Ilha que, por sua vez, está em um entreposto fluvial onde o fluxo de barcos pesqueiros é constante, promovendo a comercialização paralela de produtos nativos e troca de mercadorias.

As comunidades de Araras I (69\%) e Caxiuanã (65\%) também demonstraram um bom resultado de acesso a renda depois da implantação do sistema. Este panorama encontra alinhamento com as afirmações de Bermann (2003) quanto ao uso da fonte solar, quando alerta para o aumento do número de empregos locais e para um desenvolvimento autossustentado. Isso se deve à forma como cada participante desenvolve suas atividades de captação de renda, pois muitos apenas utilizam a energia de forma direcionada para o consumo e não como opção de uma atividade complementar de renda.

$\mathrm{O}$ fornecimento de energia por meio dos projetos para essas comunidades foi, para muitas pessoas, o primeiro acesso à eletricidade.

Em certas comunidades esse acesso já era realizado por meio de geradores a diesel, os quais eram utilizados em períodos de curta duração, dado o alto valor do litro do combustível. Quando os sistemas entraram em operação, ocorreu uma redução nos gastos dessas famílias, na medida em que não precisavam gastar com combustível para a alimentação de sistemas de geração elétrica. Isso se refletiu na aquisição em maior número de aparelhos como televisores, rádios, celulares e geladeiras.

É importante chamar a atenção de que a análise de todo este contexto identifica diretamente as considerações de Costa Jr. et al. (2013), quando destacam que a qualidade de vida engloba a capacidade de um indivíduo, inserido na comunidade, em avaliar e sintetizar todos os elementos fundamentais para estabelecer o padrão

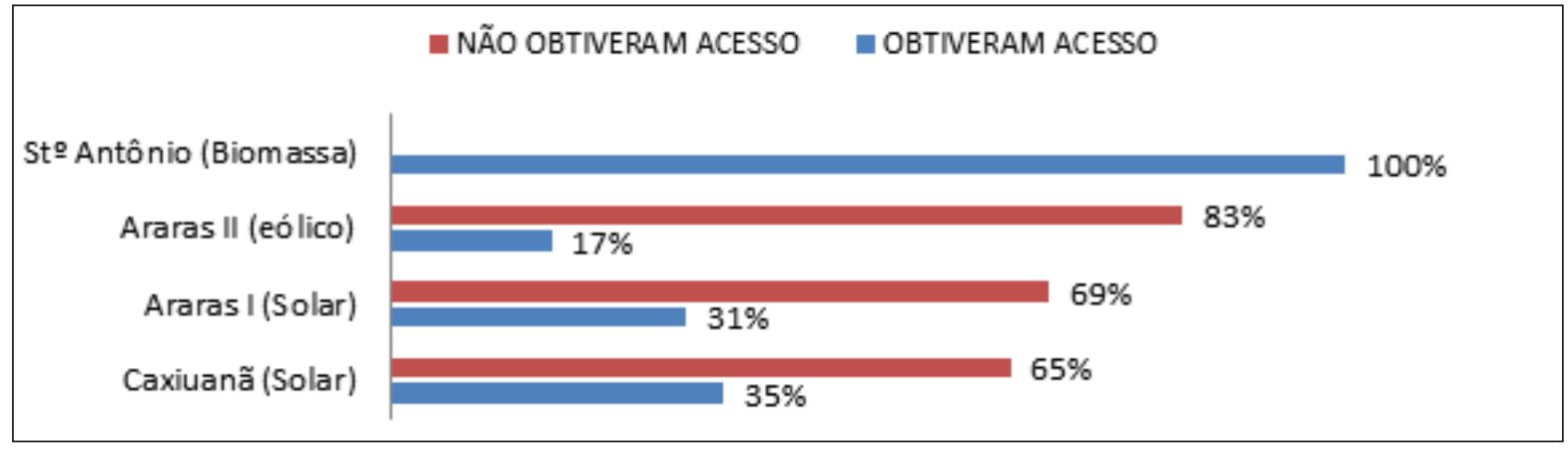

FIGURA 5 - Famílias com acesso a renda devido à implantação dos sistemas.

FONTE: Elaborado pelos autores. 
de conforto e bem-estar ideais. Este padrão de conforto passou a existir de forma mais consistente nas comunidades estudadas a partir da implantação dos projetos de geração de eletricidade.

No tocante à percepção de desenvolvimento socioeconômico por parte das comunidades, a investigação pôde observar a multiplicidade dos fatores que podem vir a estabelecer um panorama de qualidade de vida de uma comunidade, conforme Costa Jr. et al. (2013). Esta constatação foi verificada por meio dos depoimentos dos entrevistados. A Figura 6 demonstrou que as comunidades de Santo Antônio (100\%) e Araras II (89\%) apresentaram os maiores índices quando perguntadas sobre a percepção de desenvolvimento local após a implantação de seu respectivo sistema de geração de eletricidade. A primeira teve seu desenvolvimento alavancado por meio da oportunidade de trabalho que a serraria proporciona e juntamente com a demanda de mão de obra que ela passou a ter após a implantação do gaseificador e a fábrica de gelo que foi instalada após a conclusão do mesmo. Isso levou ao rápido fluxo de pessoas, em maior parte de pescadores. O próprio funcionamento do sistema de geração passou a ocupar um maior número de pessoas que vinham de ilhas vizinhas para trabalhar na comunidade.

As comunidades de Araras I (54\%) e Caxiuanã $(56 \%)$ foram entre as pesquisadas as que apresentaram o menor índice de percepção do desenvolvimento socioeconômico. Isso é resultado da forma como o sistema fotovoltaico está instalado nas comunidades, em sistemas descentralizados que fornecem eletricidade para algu- mas residências que, em certos casos, são formadas por pessoas da mesma família. Este panorama leva a um fechamento desse grupo familiar para a entrada de pessoas de fora da Ilha. No caso específico de Caxiuanã, por ser uma região de reserva florestal, tem-se uma limitação quanto ao fluxo de pessoas para a região.

É relevante destacar em toda esta análise que as quatro comunidades que foram objeto de investigação indicaram uma espécie de sentimento de exclusão antes da implantação dos projetos. A falta de eletrificação em comunidades fez com que muitas famílias deixassem de praticar atividades que poderiam contribuir para uma vida melhor, como estudar, trabalhar, manter interação com o meio social exterior.

A proposta de implantação nas quatro comunidades foi de eletrificá-las e inseri-las no meio social sem uma remuneração posterior aos executores dos projetos. Isso é confirmado quando analisada a elaboração de implantação dos mesmos, pois tudo advém de um fundo governamental. Na implantação de um projeto de geração de energia em comunidades remotas não há a possibilidade de se ter um retorno sobre o investimento, dada a situação econômica na qual se encontram as famílias que residem nessas localidades (pescadores, madeireiros ou extratores de frutos nativos), por serem de baixa renda, sendo que muitos se encontram abaixo da linha da pobreza.

Na comunidade de Santo Antônio, o fornecimento de eletricidade advém de uma usina comunitária que tem seus custos pagos pela associação que surgiu do Projeto Marajó. Porém, nas comunidades de Araras I

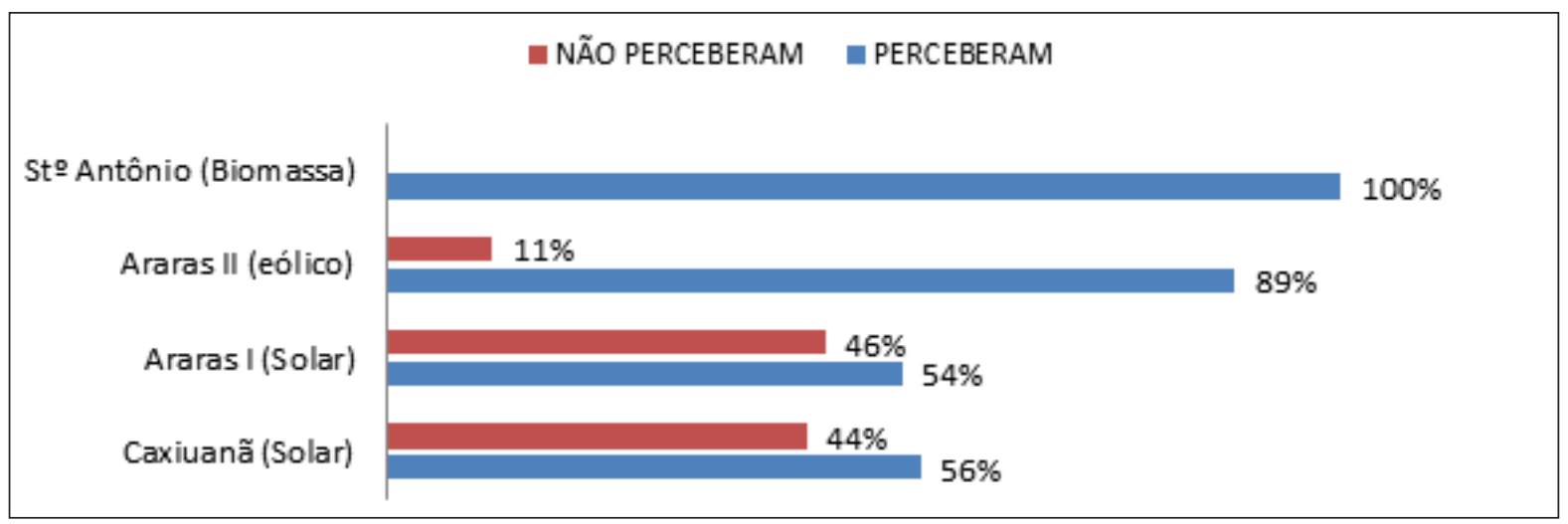

FIGURA 6 - Percepção de desenvolvimento local por parte das comunidades após a implantação dos projetos. FONTE: Elaborado pelos autores. 
e II ocorrerá um repasse de operação do sistema para a concessionária de energia paraense, as Centrais Elétricas do Pará-CELPA. As comunidades não realizam nenhum pagamento pelo fornecimento de energia até o presente momento da realização da pesquisa. Na comunidade de Caxiuanã, a responsabilidade é repassada para os donos das residências onde as placas fotovoltaicas estão instaladas e a ocorrência de algum problema é repassada para a Estação Científica Ferreira Penna, que administra os sistemas da região.

A questão da energia para usos produtivos é outro ponto fundamental quando se discute tecnologias para fontes de geração de eletricidade. Coelho e Goldemberg (2013) trabalham esta questão de maneira a discutir as lições aprendidas no Brasil e as perspectivas para a replicação em outros países em desenvolvimento. Todavia, faz-se a opção nesta oportunidade de finalizar o estudo aqui desenvolvido e direcionar a discussão sobre tecnologias para fontes de geração de eletricidade para outra oportunidade, com uma investigação mais específica.

\section{Conclusão}

Diante do objetivo de análise da qualidade de vida de comunidades da Ilha do Marajó, a partir da implantação de fontes alternativas de geração de eletricidade, e do questionamento desta investigação, que observou até que ponto a implantação de projetos a partir de fontes alternativas de geração de eletricidade na Ilha do Marajó, especialmente de biomassa, solar e eólica, contribuíram para o padrão de vida das comunidades locais, constatou-se que estes projetos de geração de eletricidade podem ser utilizados também como fator de inserção socioeconômica destas comunidades em uma condição de melhoria da qualidade de vida.

$\mathrm{O}$ estudo constatou que, apesar de interrupções no fornecimento de eletricidade nas comunidades, as mesmas registraram alto grau de satisfação, perceberam melhorias substanciais na qualidade de vida e a maior parte das famílias residentes passou a possuir pelos menos três eletrodomésticos. Porém, o acesso a renda de maneira substancial e permanente ocorreu apenas na comunidade de Santo Antônio. O principal problema identificado nos projetos pesquisados foi a dificuldade de manutenção destes após suas conclusões. Alguns projetos anteriores foram abandonados pela dificuldade financeira de reposição de peças, o que não representava cerca de $8 \%$ do custo total de implantação. Outros projetos enfrentaram problemas de gestão por parte da comunidade ou empresa responsável pela operação e pelos reparos.

Os empreendimentos são considerados viáveis e podem ser autossustentáveis desde que estabelecidos critérios a serem seguidos tanto para a população quanto para a gestão, como capacidade instalada, pagamento pelo fornecimento ou complementação dos sistemas com atividades lucrativas que decorrem de sua funcionalidade, trazendo retorno para a administração e novos investimentos para os projetos. Isso leva a uma possibilidade de surgimento de novas ações baseadas em estratégias que possam ampliar o uso das fontes biomassa, solar e eólica para a geração de eletricidade no Pará.

Por fim, é importante destacar que o esforço em direção ao uso de fontes alternativas alinhadas aos desafios competitivos e ambientais apresentados pelo panorama internacional deve ser resultado de um plano nacional sustentável e integrado. Se o planejamento do governo federal não estiver comprometido com a necessidade de transformação da matriz elétrica nacional e os discursos políticos continuarem comprometidos com a geração de PIB em curto prazo, fatalmente o crescimento do consumo de eletricidade no país irá indicar a necessidade de construção de novos grandes empreendimentos hidrelétricos no Pará. É neste sentido que se sugere o desenvolvimento de novos estudos em direção a análises da inserção social a partir de comunidades que implantaram fontes alternativas para a geração de eletricidade em outras regiões do país. 


\section{Referências}

BEEPA - Balanço Energético do Estado do Pará, 2006. Belém: BEEPA, 2007.

Bermann. C. Energia no Brasil: para quê? Para quem? Crise e alternativas para um país sustentável. São Paulo: Livraria da Física, 2003.

Borges, F. Q.; Zouain, D. M. A matriz elétrica e seu posicionamento no desenvolvimento sustentável no estado do Pará. Revista Planejamento e Politicas Públicas, Brasília: IPEA, 35, 187-221, 2010.

Bruyn, S.; Drunden, M. Sustentability and indicators in Amazon: conceptual framework for use in Amazon. Amsterdam: VRIJE, 1999.

Buss P. M. Promoção da saúde e qualidade de vida. Ciência \& Saúde Coletiva, 5(1), 163-177, 2000.

Cavalcanti, C. Política de governo para o desenvolvimento sustentável: uma introdução ao tema e a esta obra coletiva. In: Cavalcanti, C. (Org.). Meio ambiente, desenvolvimento sustentável e políticas públicas. São Paulo: Cortez, 1997.

Coelho, S. T.; Goldemberg, J. Energy access: Lessons learned in Brazil and perspectives for replication in other developing countries. Energy Policy, 61, 1088-1096, 2013.

Costa Junior, G. R.; Tonello, L.; Neves, R. L.; Ribeiro, J. C., Miranda, E. F. Qualidade de vida, estilo de vida e saúde: um artigo de revisão. Revista Amazônia, 1(1), 33-40, 2013.

DNPM - Departamento Nacional de Produção Mineral. Anuário Mineral Brasileiro. Brasília: MME, 2005.

Gaetani, M.; Huld, T.; Vignati, E.; Monforti-Ferrario, F.; Dosio, A.; Raes, F. The near future availability of photovoltaic energy in Europe and Africa in climate-aerosol modeling experiments. Renewable and Sustainable Energy Reviews, 38, 706-716, October 2014.

Infoescola. Ilha do Marajó. Disponível em: <http://www.infoescola.com/geografia/ilha-de-marajo>. Acesso em: out. 2013.

Instituto Brasileiro de Geografia e Estatística. Indicadores. Rio de Janeiro. 2008. Disponível em: <http://www.ibge.gov.br>. Acesso em: 02 ago. 2008.

Junk, W. J.; Mello, J. A. S. N. de. Impactos ecológicos das represas hidrelétricas na bacia amazônica brasileira. Estud. $A v$., São Paulo, 4(8), jan./abr. 1990.
Khare, V.; Nema, S.; Baredar, P. Status of solar wind renewable energy in India. Renewable and Sustainable Energy Reviews, 27, 1-10, Nov. 2013.

Marques Filho, A. de O.; Dallarosa, R. G. Interceptação de radiação solar e distribuição de área foliar em floresta de terra firme na Amazônia central. Revista Acta Amazônica, Manaus, 30(3), 453-470, 2000.

Minayo, M. C. S. A saúde em estado de choque. Rio de Janeiro: FASE, 1992.

Minayo, M. C. S. Qualidade de vida e saúde: um debate necessário. Ciência \& Saúde Coletiva, 5(1), 7-18, 2000.

Ministério de Minas e Energia - MME. Belo Monte vai produzir energia com respeito ao meio ambiente. Brasília, 2012. Disponível em: <http://www.mme.gov.br/mme/menu/belo_monte. html >. Acesso em: set. 2013.

Nahas, M. V. Atividade física, saúde e qualidade de vida: conceitos e sugestões para um estilo de vida ativo. Londrina: Midiograf, 2003.

Padilha, J. L.; Rendeiro, G.; Brasil, A. C. M.; Santos, R. E. de J.; Pinheiro, G. Potencial de geração de energia elétrica no Estado do Pará: utilizando a biomassa do setor madeireiro. Revista Biomassa e Energia, 2(4), 267-284, 2005.

Rameix, S. Justifications et difficultés éthiques du concept de qualité de vie. Revue Prevenir, 33, 89-103, 1997.

Rendeiro, G. Experimental analysis of assai palm biomass for energy power generation. In: 7th International Conference on Energy for a Clean environment. Lisboa: s/e, 2003.

Reis, L. B.; Fadigas, E. A. A.; Carvalho, C. E. Energia, recursos naturais e a prática do desenvolvimento sustentável. São Paulo: Manole, 2005.

Silva, M. V. M. da. A dinâmica excludente do sistema elétrico paraense. São Paulo: EP/FEA/IEE/IFUSP, 2005.

Tolmasquim, M. T.; Guerreiro, A.; Gorini, R. Matriz energética brasileira: uma prospectiva. Novos Estudos Brasileiros, 79, 47-69, nov. 2007.

Vergara, S. C. Projetos e Relatórios de Pesquisa em Administração. São Paulo: Atlas, 2009.

WCED - World Commission on Environment Development. Uma visão geral. Oxford: Universidade de Oxford, 1991. 